\title{
Factors influencing the result of superior oblique weakening procedures in patients with superior oblique overaction in horizontal strabismus
}

\author{
Junwoo Chun and Seong-Joon Kim ${ }^{*}$
}

\begin{abstract}
Background: Few studies have evaluated the surgical outcome of superior oblique weakening procedures in patients with superior oblique overaction associated with exotropia or esotropia. This study aimed to evaluate the outcome of superior oblique muscle weakening and the influencing factors in patients with superior oblique overaction.

Methods: The medical charts of 37 patients (55 eyes) with superior oblique overaction associated with esotropia or exotropia who were treated with a superior oblique weakening procedure at the Seoul National University Hospital from January 2010 to June 2017 were retrospectively reviewed. Superior oblique overaction was graded using, a 6-point scale ranging from +0.5 to +3 , and pre- and postoperative grades were recorded for all patients.

Results: The mean age of the patients was $91.81 \pm 59.37$ months. Superior oblique muscle suture spacer and superior oblique posterior tenectomy were performed for 17 (23 eyes) and 20 (32 eyes) patients, respectively. Surgical success was achieved in 15 (65.2\%) eyes in the suture spacer group and 23 (71.9\%) eyes in the posterior tenectomy group. Surgical success was achieved for $69.1 \%$ (38/55 eyes) of patients. Dissociated vertical deviation exhibited a significant negative association with the surgical success rate $(p<0.001)$.

Conclusions: There was no significant difference in surgical success rate between the superior oblique posterior tenectomy and superior oblique suture spacer groups in superior oblique overaction associated with horizontal strabismus. Associated dissociated vertical deviation can affect the surgical success of the superior oblique weakening procedure.
\end{abstract}

Keywords: Superior oblique overaction, Superior oblique weakening procedure, Dissociated vertical deviation

\section{Background}

Superior oblique weakening procedures are used to treat superior oblique overaction, A- pattern strabismus occurs due to superior oblique overaction, inferior oblique muscle palsy, and Brown syndrome. Superior oblique weakening procedures include the superior oblique

* Correspondence: ophjun@snu.ac.kr

Department of Ophthalmology, Seoul National University College of

Medicine, 101 Daehak-Ro, Jongno-Gu, Seoul 110-744, Republic of Korea muscle tenectomy, tenotomy, Z-tenotomy, silicone expander, and suture spacers.

Earlier studies have reported a $65 \%$ success rate of superior oblique lengthening using silicone expanders in Brown syndrome, $67 \%$ success of using suture spacer in Brown syndrome, and $75 \%$ success rate of superior oblique lengthening procedures with silicone expanders in A-pattern strabismus [1-3]. Other studies have reported A-pattern collapse after a superior oblique weakening procedure in 60 to $84 \%$ of patients [4-6]. 
However, there have been few studies on the surgical outcome of superior oblique weakening procedures for the superior oblique overaction associated with exotropia or esotropia.

Therefore, we aimed to investigate the clinical outcome and factors affecting the outcome of the superior oblique weakening procedure in patients with superior oblique overaction.

\section{Methods}

This study was approved by the Institutional Review Board of Seoul National University Hospital in Korea. (No. 1802-082-923) This study protocol followed the tenets of Declaration of Helsinki.

The medical charts of 37 consecutive patients (55 eyes) with superior oblique overaction, who underwent a superior oblique weakening procedure (superior oblique posterior tenectomy or superior oblique suture spacer) between January 2010 and June 2017 were retrospectively reviewed. Superior oblique posterior tenectomy was performed between January 2010 and August 2013, while the superior oblique suture spacer was performed between September 2013 and June 2017. As we believed that it would be better to avoid removing part of the muscle, a suture spacer was instead considered for the surgical techniques. All surgeries were performed by the same surgeon (SJK). Patients with superior oblique overaction associated with exotropia and esotropia were included. Those with Brown syndrome and double elevator palsy were excluded. While patients with primary superior oblique overaction were included in this study, those with secondary superior oblique overaction due to inferior oblique paresis were excluded. We also excluded patients with a history of vertical rectus muscle surgery or oblique muscle surgery.

The following patient characteristics were recorded: sex, age during surgery, refractive error determined using cycloplegic refraction, angle of deviation at a distance, dissociated vertical deviation, preoperative and postoperative superior oblique overaction, and fundus torsion were assessed using fundus photography.

The prism and alternate cover test were performed at $6 \mathrm{~m}$ for cooperative patients, and the Krimsky test was performed for uncooperative patients.

Superior oblique overaction was graded using a 6point scale ranging from +0.5 to +3 . During testing for the version of both eyes, the patients were instructed to look downward and $30^{\circ}$ laterally in both directions. When both eyes were parallel, they were considered normal and without superior oblique overaction. However, when the adducted eye was directed vertically downward, the superior oblique overaction was defined as grade $3+$. The intermediate ranges were graded $1+$ and +
2 , respectively. A grade of +0.5 was assigned in cases of minimal overaction.

The dissociated vertical deviation was distinguished by observation of the following: (1) characteristic elevation and excyclotorsion of the involved eye under cover and (2) absence of hypotropic movement of the other eye in any field of gaze. All measurements were made by the same observer (SJK).

Cycloplegic refraction was performed with $1 \%$ cyclopentolate hydrochloride. Refractive errors measured by cycloplegic refraction were recorded as spherical equivalents.

Ocular torsion was assessed by fundus photography, and Retcam (RetCam Clarity Medical Systems Inc., Pleasanton, CA) before the surgery. Retcam was conducted in pediatric patients who were unable to cooperate with patients laying in a supine position while under chloral hydrate-induced sedation. The amount of ocular torsion was determined by measuring the disc fovea angle (DFA), using public domain software (Image J; National Institutes of Health, Bethesda, MD). The DFA is defined as the angle between a horizontal line extending from the center of the optic disc and a line from the center of the disk to the fovea.

Stereopsis was measured using the Titmus Fly Stereo Test (Stereo Optical, Chicago, IL), in cooperative patients, before and after surgery.

All surgical procedures were conducted by the same surgeon (SJK) under general anesthesia. Surgical success was defined as the complete absence of superior oblique overaction 1 month after surgery. Failure of operation was defined as the incomplete reduction or elimination of superior oblique overaction after surgery.

We evaluated the success rate and factors influencing surgical response, by comparing the data of patients who underwent the unilateral and bilateral superior oblique muscle weakening procedures. We also compared the surgical success rate and factors, according to the procedure (posterior tenectomy, suture spacer). Finally, we compared the difference between the surgical success and failure groups. Statistical analyses were performed using SPSS Statistics 19.0 (IBM Corp., Armonk, NY). $P<0.05$ was considered to be statistically significant. The independent t-test, chi-square test, Fisher's exact test, and the Mann-Whitney U test were used for statistical analyses.

\section{Results}

Among 37 consecutive patients (55 eyes) with superior oblique overaction, 19 patients (19 eyes) underwent the unilateral superior oblique weakening procedure and 18 patients (36 eyes), underwent the bilateral procedure. Seventeen patients (23 eyes) were treated with the superior oblique suture spacer approach, and 20 patients (32 eyes) 
Table 1 Surgical methods and number of patients (eyes)

\begin{tabular}{llll}
\hline & $\begin{array}{l}\text { Unilateral } \\
\text { group }\end{array}$ & $\begin{array}{l}\text { Bilateral } \\
\text { group }\end{array}$ & Total \\
\hline Suture spacer group & $11(11)$ & $6(12)$ & $17(23)$ \\
Posterior tenectomy group & $8(8)$ & $12(24)$ & $20(32)$ \\
Total & $19(19)$ & $18(36)$ & $37(55)$ \\
\hline
\end{tabular}

were treated with superior oblique posterior tenectomy (Table 1).

Three patients ( 6 eyes) had esotropia, while 34 patients (49 eyes) had exotropia. The mean age was $91.81 \pm$ 59.37 months. The male-female ratio was 16 (25 eyes): 21 (30 eyes).

Horizontal strabismus procedure was successful in 31 patients $(83.8 \%)$ while failure was reported in 6 patients (surgical success was defined when values $\leq 5$ and $\leq 10$ prism were observed esotropia and exotropia, respectively).

There was no significant correlation with between successful horizontal strabismus procedure and superior oblique weakening procedure ( $p=0.162$, Fisher's exact test).

Similary, no significant differences in patient characteristics and surgical success rate were found between the superior oblique posterior tenectomy and superior oblique suture spacer groups (Table 2).

In contrast, the occurrence of ocular incyclotorsion significantly differed between the unilateral and bilateral groups $(p=0.013)$. However, the groups did not differ significantly in any other factors, such as type of surgical procedure, age during surgery, refractive error, dissociated vertical deviation, preoperative superior oblique overaction, and associated horizontal strabismus (either exotropia or esotropia). Moreover, no difference was identified in the surgical success rate between the two groups (Table 3 ).

There were no significant differences in any variable except dissociated vertical deviation between the surgical success and failure groups. There was a statistically significant difference in the dissociated vertical deviation $(p<0.001)$ between the two groups, and the rate of surgical success decreased with an increase in dissociated vertical deviation (Table 4).

Stereopsis was measured for 16 of 37 patients at 1 month before and 1 month after the surgery. Ten patients $(62.5 \%)$ showed an increase of more than two octaves, while the remaining six (37.5\%) showed a change lower than two octaves.

\section{Discussion}

Superior oblique posterior tenectomy and the superior oblique muscle suture spacer approach are widely used procedures for superior oblique weakening [7]. Earlier studies have suggested that they are effective in weakening superior oblique overaction and also for correcting the A-pattern $[4,8]$.

The surgical success rate of the superior oblique weakening procedure was $69.1 \%$ (38/55 eyes) in this study. Although the improvements in the A-pattern after surgery were not investigated, we evaluated the superior oblique overaction with detailed grading at duction and version.

Superior oblique weakening procedures cannot guarantee binocular vision due to the ocular torsion after surgery for the superior oblique overaction associated with exotropia or esotropia. However, our study showed that $62.5 \%$ $(10 / 16)$ of patients experienced an increase in stereopsis and no patient showed a decrease in stereopsis.

The normal range of DFA is $5.6^{\circ}-8^{\circ}$ [9-13]. DFA was $3.08^{\circ} \pm 7.00^{\circ}$ in the unilateral group, indicative of mild incyclotorsion. However, it was $-2.74^{\circ} \pm 6.60^{\circ}$ in the bilateral group, indicative of greater incyclotorsion, which is evident of superior oblique overaction. Incyclotorsion was naturally greater in the bilateral group.

There were no significant differences in the patient characteristics and surgical success rates between the superior oblique suture spacer and posterior tenectomy groups. Suture spacers are generally thought to have a greater surgical effect, but there were no difference. There were no significant differences in any variable

Table 2 Comparison according to the method of superior oblique weakening

\begin{tabular}{lllll}
\hline & Total & Suture spacer & Posterior tenectomy & $P$-value \\
\hline Sex (M: F) $(N=37)$ & $16: 21$ & $7: 10$ & $9: 11$ & 0.815 \\
Age at operation (months) $(N=37)$ & $91.81 \pm 59.37$ & $84.06 \pm 41.24$ & $98.40 \pm 71.74$ & 0.472 \\
Associated horizontal strabismus (PD) $(N=37)$ & $20.19 \pm 18.98$ & $18.35 \pm 18.07$ & $21.75 \pm 20.04$ & 0.595 \\
Surgical success (success: fail) & $38: 17$ & $15: 8$ & $23: 9$ & 0.598 \\
Refractive error (spherical equivalent) & $0.36 \pm 2.34$ & $0.20 \pm 2.13$ & $0.48 \pm 2.50$ & 0.656 \\
DVD (positive: negative) & $23: 32$ & $9: 14$ & $14: 18$ & 0.732 \\
Preoperative SO overaction (+ 0.5 to +3$)$ & $1.59 \pm 0.47$ & $1.83 \pm 0.32 \pm 0.49$ & $-1.50 \pm 7.64$ \\
Torsion (-: intorsion, + : extorsion) degree $(N=43)$ & $-1.23 \pm 6.38$ & $-0.32 \pm 6.69$ & & 0.597 \\
\hline
\end{tabular}

$P D$ prism diopters, $S O$ superior oblique, DVD dissociated vertical deviation 
Table 3 Comparison of the unilateral group and bilateral group

\begin{tabular}{lllll}
\hline & Total & Unilateral group & Bilateral group & $P$-value \\
\hline Sex $(\mathrm{M}: \mathrm{F})(\mathrm{N}=37)$ & $16: 21$ & $7: 12$ & $9: 9$ & $104.67 \pm 68.70$ \\
Age at operation (months) $(\mathrm{N}=37)$ & $91.81 \pm 59.37$ & $79.63 \pm 46.26$ & $19.44 \pm 20.60$ \\
Associated horizontal strabismus (PD) $(\mathrm{N}=37)$ & $20.19 \pm 18.98$ & $20.89 \pm 17.85$ & $12: 24$ & 0.204 \\
SO weakening procedure & $23: 32$ & $11: 8$ & $25: 11$ & 0.820 \\
(suture spacer: posterior tenectomy) & & & 0.079 \\
Surgical success (success: fail) & $38: 17$ & $13: 6$ & $0.53 \pm 2.70$ \\
Refractive error (spherical equivalent) & $0.36 \pm 2.34$ & $0.05 \pm 1.46$ & $16: 20$ & 0.938 \\
DVD (positive: negative) & $23: 32$ & $7: 12$ & $1.58 \pm 0.50$ & 0.400 \\
Preoperative SO overaction (+ 0.5 to +3$)$ & $1.59 \pm 0.47$ & $1.60 \pm 0.43$ & $-2.74 \pm 6.60$ & 0.587 \\
Torsion (-:intorsion, + :extorsion) degree $(N=43)$ & $-1.23 \pm 6.38$ & $3.08 \pm 7.00$ & $0.013^{\mathrm{a}}$ \\
\hline
\end{tabular}

$P D$ prism diopters, SO superior oblique, DVD dissociated vertical deviation

a $p<0.05$ independent t-test

except the dissociated vertical deviation between the surgical success and failure groups.

The cause of dissociated vertical deviation is unknown. Several etiological theories have been proposed, including superior rectus hypofunction, anomalous impulses from an involuntary divergence center, aberrations of postural tonus mechanisms of the extraocular musculature, bilateral paresis of the depressor muscles, and deficiency in the optomotor impulse from the inferonasal retinal quadrants. Dissociated vertical deviation may also result from superior oblique hypofunction or an alternating innervational insufficiency of the superior oblique muscles [14-16]. According to Wright et al. [17], superior oblique weakening procedures can cause complications in patients with preexisting dissociated vertical deviation, as the weakening of the superior oblique can exacerbate dissociated vertical deviation.

In our study, the success rate of the superior oblique weakening procedures significantly decreased with the presence of dissociated vertical deviation. Superior oblique overaction accompanied with dissociated vertical deviation seems to have a different etiology than superior oblique overaction alone. Although the cause of superior oblique overaction in patients with horizontal strabismus and the cause of accompanying dissociated vertical deviation are unknown. It can be assumed that surgical outcomes could worsen when superior oblique overaction and dissociated vertical deviation coexist.

Our study has a few limitations. First, this was a retrospective study. Second, the A-pattern was not evaluated. Third, Retcam, rather than fundus photography, was used for noncompliant pediatric patients. To the best of our knowledge, the cyclotorsion induced by choral hydrate has not been reported ever. However, given that cyclotorsion was possible in the supine position [18], the failure to control for this variable was included as a limitation of this study. An internal fixator was not used for accurate measurement of ocular torsion and postoperative torsional change was not evaluated. Finally, the effect of horizontal strabismus surgery on the surgical result of superior oblique weakening procedure was not evaluated.

Table 4 Comparison of the success group and failure group

\begin{tabular}{lllll}
\hline & Total & Success group & Failure group & $P$-value \\
\hline Sex $(\mathrm{M}: \mathrm{F})(\mathrm{N}=37)$ & $16: 21$ & $11: 16$ & $5: 5$ & 0.716 \\
Age at operation (months) $(\mathrm{N}=37)$ & $91.81 \pm 59.37$ & $96.10 \pm 38.95$ & $90.22 \pm 65.93$ & $16.58 \pm 3.19$ \\
Associated horizontal strabismus (PD) $(\mathrm{N}=37)$ & $20.19 \pm 18.98$ & $24.51 \pm 7.75$ & $8: 9$ & 0.291 \\
SO weakening procedure & $23: 32$ & $15: 23$ & $0.30 \pm 1.86$ \\
(suture spacer: posterior tenectomy) & & $0.51 \pm 3.23$ & $13: 4$ \\
Refractive error (spherical equivalent) & $0.36 \pm 2.34$ & $10: 28$ & $1.76 \pm 0.44$ \\
DVD (positive: negative) & $23: 32$ & $1.51 \pm 0.47$ & $-3.26 \pm 6.59$ & 0.797 \\
Preoperative SO overaction (+ 0.5 to + 3) & $1.59 \pm 0.47$ & $0.12 \pm 7.29$ & $0.001^{\text {a }}$ \\
Torsion (-: intorsion, +: extorsion) degree $(N=43)$ & $-1.23 \pm 6.38$ & 0.150 \\
\hline
\end{tabular}

$P D$ prism diopters, $S O$ superior oblique, $D V D$ dissociated vertical deviation 


\section{Conclusions}

To the best of our knowledge, this is the first study, in which the superior oblique weakening procedure was evaluated in terms of duction and version. Associated dissociated vertical deviation can affect the surgical success of the superior oblique weakening procedure.

\section{Abbreviation}

DFA: Disc fovea angle

\section{Acknowledgements}

None.

\section{Authors' contributions}

Involved in conception and design (CJW, SJK) and conduct of the study (CJW, SJK); collection, management and interpretation of data (CJW, SJK); data analysis (CJW, SJK); writing the article (CJW, SJK); and preparation, review, and approval of the manuscript (CJW, SJK). CJW contributed to the manuscript as the first authors. SJK contributed to the manuscript as the corresponding authors. All authors have read and approved the manuscript.

\section{Funding}

None.

\section{Availability of data and materials}

The datasets used and/or analysed during the current study available from the corresponding author on reasonable request.

\section{Ethics approval and consent to participate}

This study received ethical approval from the Institutional Review Board of the Seoul National University Hospital. The Ethics Committee study protocol number was 1802-082-923 and the IRB granted a waiver of consent for this retrospective chart review study.

\section{Consent for publication}

Not applicable.

\section{Competing interests}

No conflicts of interest and have no proprietary interest in any of the materials mentioned in this article.

Received: 14 July 2020 Accepted: 8 October 2020

Published online: 20 October 2020

\section{References}

1. Wright KW. Results of the superior oblique tendon elongation procedure for severe Brown's syndrome. Trans Am Ophthalmol Soc. 2000;98:41-8 discussion 48-50.

2. Suh DW, Guyton DL, Hunter DG. An adjustable superior oblique tendon spacer with the use of nonabsorbable suture. J AAPOS. 2001:5:164-71.

3. Awadein A, Gawdat G. Comparison of superior oblique suture spacers and superior oblique silicone band expanders. J AAPOS. 2012;16:131-5.

4. Shuey TF Jr, Parks MM, Friendly DS. Results of combined surgery on the superior oblique and horizontal rectus muscles for A-pattern horizontal strabismus. J Pediatr Ophthalmol Strabismus. 1992;29:199-201.

5. Lee SY, Rosenbaum AL. Surgical results of patients with A-pattern horizontal strabismus. J AAPOS. 2003:7:251-5.

6. Ron Y, Snir M, Axer-Seigel R, Friling R. Z-tenotomy of the superior oblique tendon and horizontal rectus muscle surgery for A-pattern horizontal strabismus. J AAPOS. 2009;13:27-30

7. Jethani J, Shah K, Amin S. Effect of bilateral superior oblique split lengthening on torsion. Indian J Ophthalmol. 2015;63:250-3.

8. Bardorf CM, Baker JD. The efficacy of superior oblique split Z-tendon lengthening for superior oblique overaction. J AAPOS. 2003;7:96-102.

9. Williams TD, Wilkinson JM. Position of the fovea centralis with respect to the optic nerve head. Optom Vis Sci. 1992;69:369-77.

10. Madigan WP Jr, Katz NN. Ocular torsion-direct measurement with indirect ophthalmoscope and protractor. J Pediatr Ophthalmol Strabismus. 1992;29: $171-4$.
11. Rohrschneider K. Determination of the location of the fovea on the fundus. Invest Ophthalmol Vis Sci. 2004:45:3257-8.

12. Kothari MT, Venkatesan G, Shah JP, Kothari K, Nirmalan PK. Can ocular torsion be measured using the slitlamp biomicroscope? Indian J Ophthalmol. 2005;53:43-7.

13. Jethani J, Seethapathy G, Purohit J, Shah D. Measuring normal ocular torsion and its variation by fundus photography in children between 5-15 years of age. Indian J Ophthalmol. 2010;58:417-9.

14. Crone RA. Alternating hyperphoria. Br J Ophthalmol. 1954;38:591-604

15. McCall LC, Rosenbaum AL. Incomitant dissociated vertical deviation and superior oblique overaction. Ophthalmology. 1991;98:911-7 discussion 917-8.

16. White JW. Paralysis of the superior rectus muscle. Trans Am Ophthalmol Soc. 1933;31:551-84.

17. Wright KW, Strube YNJ Pediatric ophthalmology and strabismus, 3rd ed. Oxford University Press; 2021. p 329-330.

18. Kim HJ, Joo CK. Ocular cyclotorsion according to body position and flap creation before laser in situ keratomileusis. J Cataract Refract Surg. 2008;34: 557-61.

\section{Publisher's Note}

Springer Nature remains neutral with regard to jurisdictional claims in published maps and institutional affiliations.
Ready to submit your research? Choose BMC and benefit from:

- fast, convenient online submission

- thorough peer review by experienced researchers in your field

- rapid publication on acceptance

- support for research data, including large and complex data types

- gold Open Access which fosters wider collaboration and increased citations

- maximum visibility for your research: over $100 \mathrm{M}$ website views per year

At $\mathrm{BMC}$, research is always in progress.

Learn more biomedcentral.com/submissions 